\title{
Divulgação científica e ensino de língua portuguesa: reflexões sobre uma proposta de trabalho no ensino médio
}

Daiana Campani"

Luciene Juliano Simões*"

\section{Resumo}

Muitas escolas brasileiras já adotaram uma metodologia de ensino pela pesquisa, contribuindo, dessa forma, para o letramento científico dos estudantes. Nesse contexto, é papel da escola básica oferecer oportunidades para que estudantes-pesquisadores, além de divulgarem suas pesquisas para seus pares, possam também divulgá-las a um público não especialista. Este artigo discute os resultados de uma proposta pedagógica que buscou levar a divulgação científica para a sala de aula de língua materna. A proposta, aplicada em uma escola pública de ensino médio técnico, culminou com a produção de um texto pertencente ao gênero discursivo notícia na esfera do jornalismo de divulgação científica. Os resultados evidenciaram a importância de se trabalhar com a divulgação científica e reafirmaram a necessidade de que as propostas de ensino de língua materna estejam vinculadas às práticas sociais. Além disso, reforçaram a importância da interação entre professora e estudantes e, também, entre os próprios estudantes.

Palavras-chave: Ensino de língua portuguesa. Gêneros discursivos. Divulgação científica.

\section{O ensino pela pesquisa}

O ensino pela pesquisa já é adotado em muitas escolas brasileiras de educação básica, proposta que ganha respaldo com a publicação da Base Nacional Comum Curricular (BRASIL, 2017), que menciona o conceito de "letramento científico" e apresenta, na área de Linguagens e suas Tecnologias, o "campo das práticas de estudo e pesquisa" como um dos campos prioritários de atuação social. A BNCC (BRASIL, 2017, p. 480) sugere

\footnotetext{
* Doutoranda em Linguística Aplicada na Universidade do Vale do Rio dos Sinos (Unisinos) e professora na educação básica e no ensino superior. Seus interesses de pesquisa são ensino de língua portuguesa e formação inicial e continuada de professores. E-mail: daiana.campani@liberato.com.br

** Professora e pesquisadora do Programa de Pós-Graduação em Letras da UFRGS, onde atua na linha de pesquisa de Linguística Aplicada e orienta estágios de docência de língua portuguesa na escola básica. Seus interesses de pesquisa são a aprendizagem da língua portuguesa, tanto falada como escrita, e o ensino de língua portuguesa em contextos escolares. E-mail: luciene.simoes3@gmail.com
}

Data de submissão: set. 2020 - Data de aceite: nov. 2020 http://dx.doi.org/10.5335/rdes.v16i3.11472 
um trabalho com textos/discursos "que circulam tanto na esfera escolar como na acadêmica e de pesquisa, assim como no jornalismo de divulgação científica”.

Nesse contexto, este artigo discute uma proposta de trabalho com a divulgação científica em sala de aula de Língua Portuguesa. A divulgação científica tem como objetivo discutir o conhecimento não de cientista para cientista, mas entre o cientista e o público em geral, e a proposta foi elaborada a partir do pressuposto de que é papel da escola básica proporcionar oportunidades para a discussão sobre 0 assunto e sobre o papel da linguagem nessa tarefa. Ela foi aplicada por uma das autoras deste artigo, professora da disciplina de Língua Portuguesa, em três turmas de $1^{\circ} \mathrm{s}$ anos de uma escola pública gaúcha de ensino técnico integrado ao ensino médio. A instituição tem uma contribuição reconhecida no que se refere ao ensino pela pesquisa $\mathrm{e}$ ao estímulo à disseminação científica, aqui definida, a partir de Zamboni (2001), como a circulação da ciência entre especialistas. Essa escola realiza, todos os anos, uma feira científica internacional, que recebe jovens pesquisadores da educação básica. Apesar de a escola ser de ensino médio, há dez anos ampliou essa feira, em uma versão Júnior, para receber também estudantes de ensino fundamental de todo o Brasil e, mais recentemente, até mesmo da educação infantil.

Nesse contexto, é inegável a oportunidade de essa escola contribuir para que seus estudantes-pesquisadores reflitam não só sobre a disseminação, mas também sobre a divulgação da ciência. De acordo com Nunes (2019, p. 14),

[...] a comunicação da ciência desempenha um importante papel, uma vez que oportuniza ao público geral o contato com descobertas científicas; também possibilita a prática democrática, pois coloca em evidência abordagens especializadas, a fim de suscitar no leitor possíveis discussões. É desta forma que a sociedade se transforma: quando os experimentos e descobertas da ciência chegam ao público não especializado, de forma ativa e participativa.

Para contribuir com essa discussão, foi realizada uma proposta pedagógica em sala de aula de língua materna que culminou com a produção, por parte desses estudantes, de um texto pertencente ao gênero discursivo notícia na esfera do jornalismo de divulgação científica, voltado para crianças do ensino fundamental da região, a partir da escolha de um projeto de pesquisa apresentado por pesquisadores mirins nessa feira científica da escola. É evidente, aqui, que a prática é de jornalismo escolar; neste caso, produzido por estudantes-pesquisadores de ensino médio, tendo em vista interlocutores do ensino fundamental. Essa proposta partiu de uma concepção de aprendizagem e de linguagem como interação - interação entre professora e estudante, entre colegas, entre estudantes do ensino médio e do ensino fundamental ou educação infantil e o meio social. Tal concepção está fundamentada nas ideias de Bakhtin (2003) e toma, por 
isso, o conceito de gênero discursivo como base para todas as decisões didáticas. A proposta pedagógica dialoga também com ideias sobre a divulgação científica, a partir de trabalhos como Vogt (2003), Giering e Souza (2013) e Nunes (2019).

\section{Concepção de linguagem: interação e gêneros discursivos}

As decisões didáticas alinham-se às ideias de Simões et al. (2012, p. 38), segundo as quais, na aula de língua materna, tem-se como princípio "traduzir em trabalho sobre a linguagem, primeiro, uma concepção interacionista de linguagem e, derivadamente, um conjunto sempre crescente de conhecimentos e competências de língua que seja compatível com tal concepção". As autoras lançam, nessa obra, uma reflexão a respeito de qual é o "recado" que a aula de português propõe-se a dar, e esse questionamento é respondido quando afirmam que "o objeto de ensino é o trabalho sobre a linguagem" e que

[...]aprendizagem se traduz por novas formas de participação no mundo social, que se abrem a partir da experiência com novas práticas de letramento e a partir de novas compreensões das práticas já conquistadas (SIMÕES et al., 2012, p. 42).

A partir desse questionamento, foi possível pensar que a proposta que aqui se discute proporcionaria o contato dos estu- dantes com uma - para a maioria deles nova forma de participação em sociedade, a partir de uma nova experiência de prática de letramento, mais especificamente de letramento científico (SILVA, 2020). Como eram estudantes de $1^{\circ}$ ano, as práticas da cultura científica da escola ainda eram muito recentes para eles. Muitos vinham de escolas que faziam feiras internas, mas nem todos participavam dessa grande feira externa ou discutiam efetivamente a disseminação e a divulgação da ciência. Seria, pois, uma oportunidade de debater ciência, letramento científico e o seu papel para uma sociedade democrática. Discutir os gêneros que circulam nessa esfera, suas diferenças e os critérios de confiabilidade de uma verdadeira notícia de divulgação científica (e não uma fake news) são oportunidades que a aula de língua busca proporcionar.

Simões et al. (2012) ainda sugerem que o trabalho com produção textual na escola vá além daquelas práticas corriqueiras de se fazer um texto, em duas horas, com base em uma temática enunciada de maneira curta. Pelo contrário, elas propõem que os textos sejam produzidos com vistas a interlocutores reais e seja desdobrada em um conjunto de tarefas. Da mesma forma, as autoras recomendam que o professor pense em um projeto que, de fato, irá despertar engajamento nos estudantes e apresente temáticas e situações de comunicação com que eles lidem produtivamente. Conhecer, pois, 
o universo desses estudantes é crucial. Considerando que a aprendizagem ocorre por meio da participação, é fundamental que as atividades propostas tenham sentido para eles. Para as autoras, essa construção do engajamento, da necessidade e do interesse deve ser alcançada coletivamente em sala de aula, em um trabalho interacional. Nesse sentido, ir à feira (que, importante mencionar, não ocorre no pátio da escola e sim em um grande pavilhão da cidade), entrar em contato com outros pesquisadores, ler seus textos orais e escritos, discutir com os outros colegas do grupo a sua produção textual são formas de ampliar a participação social, o exercício de cidadania e a interação com a comunidade.

Ao partir de uma concepção de linguagem como prática interacional, o conceito de gêneros discursivos também passa a ser crucial para a condução da proposta. Para Bakhtin (2003), segundo o qual há um vínculo indissociável entre a utilização da linguagem e a atividade humana, os gêneros do discurso são tipos relativamente estáveis de enunciados que emergem das inúmeras atividades humanas. Para o autor, gêneros e atividades são "mutuamente constitutivos"; "o agir humano não se dá independente da interação; nem o dizer fora do agir" (FARACO, 2009, p. 126). São práticas comunicativas que são construídas e reconstruídas nos processos interacionais de que os sujeitos participam. Segundo a teoria bakhtiniana, são três as dimensões constitutivas dos gêneros: conteúdo temático, estilo e construção composicional. Dessas dimensões, o estilo será tomado como base para a análise dos textos dos estudantes, ao longo do artigo.

\section{A divulgação científica midiática para crianças}

A divulgação científica e a divulgação científica midiática (DCM), neste artigo, são entendidas a partir Vogt (2003), Giering e Souza (2013) e Nunes (2019). Vogt (2003) apresenta o conceito de cultura científica, pois acredita que o processo que envolve o desenvolvimento científico é um processo cultural, seja no ponto de vista de sua produção e disseminação entre os pares, seja no de sua circulação no ensino ou, ainda, de sua circulação na sociedade em geral. $\mathrm{O}$ autor apresenta um modelo do processo de desenvolvimento da cultura científica representado em forma de espiral. No primeiro quadrante dessa espiral, da produção e difusão $d a$ ciência, os cientistas são os destinadores e os destinatários da ciência; no segundo, do ensino da ciência e da formação de cientistas, cientistas e professores destinam informações para os estudantes de todos os níveis; no terceiro, do ensino para ciência, cientistas, professores e diretores de museus destinam informações para os estudantes e um público jovem; por fim, no quarto, da divulgação da ciência, jornalistas e cientistas destinam informa- 
ções para a sociedade em geral. Embora, para o autor, os sistemas de ensino fundamental e médio estejam no segundo quadrante; as feiras de ciências, no terceiro; e as revistas de divulgação científica e os jornais, no quarto, a proposta pedagógica a ser relatada partiu da visão de que a feira científica em que as ações aqui socializadas ocorreram também poderia atingir esse quarto quadrante, já que um grande número de visitantes - não só estudantes - assiste aos trabalhos, e os textos que são o produto final da proposta seriam lidos pela sociedade como um todo, ao serem, efetivamente, publicados em uma coluna no jornal da cidade voltada à feira e em redes sociais. É interessante destacar também o papel da retroalimentação dessa espiral, uma vez que todos os quadrantes estão inter-relacionados.

Giering e Souza (2013) abordam o conceito de DCM apontando que ela se situa na intersecção de três discursos: 0 científico, o didático e o midiático. Para as autoras, esse discurso tem uma dupla finalidade: informar o leitor (fazer-saber) e, ao mesmo tempo, captar seu interesse (fazer-sentir). É importante apontar que, na proposta pedagógica a ser discutida neste artigo, o discurso não se restringiu ao didático ou ao científico, pois foi possível que os estudantes, efetivamente, assumissem o papel de divulgadores da ciência, na posição de "jornalistas por um dia", criando textos que estão sendo divulgados na mídia, ultrapassando os muros da escola.

Uma vez que, nesta proposta didática, o interlocutor selecionado é o leitor infantil e juvenil, assim representado tendo em vista o recorte dos estudantes de educação infantil e ensino fundamental, foi relevante o recurso a estudos da DCM para crianças. Para Giering e Souza (2013), o texto de DCM voltado a crianças é destinado a um leitor que está em processo de formação intelectual e talvez não esteja interessado, necessariamente, em temáticas científicas. Entre as estratégias para atingir o fazer-saber e o fazer-sentir, as autoras apresentam apelo à modalidade alocutiva da interpelação (uso do pronome "você); empregos de verbos no modo imperativo, de frases interrogativas ou exclamativas e de avaliações emotivas de um objeto, ser ou ação; referências a temas e situações supostamente conhecidas do leitor; antecipação de possíveis questionamentos ou avaliações do leitor e chamada de atenção para o fato de que esse leitor mirim aprendeu algo novo.

O trabalho de Nunes (2019) também se dedica à DCM voltada para crianças. A pesquisadora buscou identificar elementos linguístico-discursivos e icônicos de patemização em textos. A patemização é definida como "uma estratégia - que visa captar e seduzir o leitor — utilizada pelo locutor, o qual mobiliza um conjunto de categorias discursivas para organizar uma interação pelo afeto" (NUNES, 2019, p. 13). O trabalho apresenta dados que mostram que a infância é a fase em que há mais distanciamento da ciência; daí a importância da discussão sobre o assunto. 
Algumas das estratégias patêmicas citadas pela pesquisadora, além das já mencionadas por Giering e Souza (2013), são as seguintes: abertura explosiva do texto (início em forma de pergunta), interjeições, palavras encontradas em histórias infantis, situações que suscitam nojo, humor, fatos inusitados, ludicidade, relação com o cotidiano da criança, antropomorfização da natureza, uso de linguagem própria da criança, entre outras estratégias.

\section{O gênero discursivo notícia na esfera do jornalismo de divulgação científica}

Quando se pensa no gênero discursivo notícia e em seu conteúdo temático, na esfera do jornalismo de divulgação científica, o texto precisa abordar os resultados finais ou parciais de um fazer científico, relevantes para a comunidade. As respostas às seis questões fundamentais típicas de uma notícia que devem ser respondidas no texto relacionam-se a essa novidade científica: quem foram os cientistas, que descobriram o quê, onde, quando, com qual justificativa (por quê), com qual metodologia (como), porém sem $o$ aprofundamento de uma reportagem.

Em relação a sua construção composicional, a notícia compõe-se de título, geralmente subtítulo ou linha de apoio, lead e detalhamento. Pode ainda conter fotos, ilustrações e legendas. Em relação ao seu estilo, dimensão que, para Bakhtin, em um gênero, está fortemente ligada ao conteúdo temático, a linguagem precisa ser simples, objetiva e clara, buscando estratégias para informar e, ao mesmo tempo, captar a atenção do leitor. Todos os conceitos científicos devem ser explicados. Para isso, apresenta definições, apostos, comparações ou analogias, sendo um texto diferente de artigos científicos produzidos para revistas científicas especializadas ou dos relatórios produzidos para as feiras científicas, em que o autor escreve de cientista para cientista. $\mathrm{O}$ autor precisa escrever para leitores não familiarizados com o tema da pesquisa ou até mesmo com ciência. Conforme a revisão das ideias de Nunes (2019), no caso do leitor mirim, o jornalista pode fazer uso de estratégias patêmicas. É um texto, se feito pelo jornalista, em terceira pessoa. Porém, diferente de uma notícia não científica, o texto pode valer-se de expressões avaliativas ou qualificadoras, conforme apontamentos da autora. É um texto veiculado em jornais, revistas ou blogues de acesso popular.

\section{As ações pedagógicas}

O trabalho envolveu em torno de 90 estudantes, divididos em três turmas, com idades variando entre 14 e 16 anos. O Quadro 1 resume as ações pedagógicas realizadas. A ênfase deste artigo é dada à Etapa 3 do quadro; contudo, optou-se por relatar etapas anteriores que foram importantes para mostrar que os estudantes já haviam trabalhado com outros gêneros discursivos que eram, a todo momento, comparados com a notícia. 
Quadro 1 - As etapas da proposta pedagógica

\begin{tabular}{|l|}
\hline \multicolumn{1}{|c|}{ Etapas } \\
\hline $\begin{array}{l}\text { 1. Estudo dos gêneros "crônica" e "notícia", a partir de uma arti- } \\
\text { culação entre crônicas do livro Imaginário cotidiano, de Moacyr } \\
\text { Scliar (2001), e notícias que deram origem aos textos de tal autor }\end{array}$ \\
\hline $\begin{array}{l}\text { 2. Estudo das normas de referências e citações da ABNT dentro } \\
\text { de textos científicos. }\end{array}$
\end{tabular}

de textos científicos.

Produto final:
produção textual

Período

Crônicas para o concurso da institui- Maio

ção, que premia os melhores contos, junho

crônicas e poemas dos estudantes

2019

com a publicação de um livro e a entrega de um troféu.

Produção de capítulo de referencial teórico para o relatório de uma atividade prática na área da eletrônica, com a disciplina "Projetos de Pesquisa".

3. Estudo da notícia na esfera do jornalismo de DC para jovens e adultos e para crianças.

Sub-etapas:

a) Leitura da notícia "Estudo explica por que cachorros são sensíveis e sociáveis" (ESTUDO..., 2017). Exercícios envolvendo o texto e as características do gênero. Discussão sobre ciência na sociedade, fake news e a DCM. Explicação da proposta a ser desenvolvido.

b) Leitura e discussão de textos de DCM infantil. Discussão sobre a DCM infantil, as características do gênero notícia para crianças e as diferenças entre a notícia e o artigo para crianças na esfera do jornalismo de DC. Textos analisados:

- "A difícil relação entre sono do adolescente, humor e horário escolar" (TARCIA, 2018)

- "Ai, que fedor!" (LORETTO, 2016)

- "De onde vem a sensação boa de quando matamos a sede?" (SOARES, 2019a)

- "Fungos para a saúde bucal?!" (SOARES, 2019b)

- "Lagarto esquentadinho" (CHAGAS, 2016)

c) Tarefa em grupos: divisão de estratégias patêmicas elencadas por Nunes (2019) para apresentação aos colegas, por meio de exemplos encontrados nos textos citados no item "b".

d) Divisão dos grupos para as entrevistas na feira.

e) Discussão sobre a postura do jornalista e dicas de como ser um "jornalista por um dia", por meio de um vídeo feito especialmente para nosso projeto pela aluna de Jornalismo da UFRGS Bibiana Costa Davila, também estagiária do jornal Zero Hora e ex-aluna do Curso Técnico de Eletrônica de nossa escola.

f) Ida à feira para a realização das entrevistas.

g) Socialização, em sala de aula, sobre os resultados encontrados nas entrevistas com cientistas do ensino fundamental. Discussão sobre a linguagem de popularização da ciência encontrada (ou não) nos trabalhos apresentados na mostra do ensino médio, também visitada pelos estudantes. Avaliação da validade da tarefa por parte dos estudantes.

h) Produção e entrega das notícias.

i) Leitura das notícias pelos colegas de outros grupos, com preenchimento da ficha de avaliação e de sugestões.

j) Leitura, por parte da professora, dos textos originais e das fichas de avaliação com sugestões dos colegas. Retorno aos estudantes, por meio de bilhetes. A esta etapa, não foi atribuída nota.

k) Reescrita por parte dos estudantes.

I) Nova avaliação por parte da professora e atribuição de nota. Feedback oral por parte da professora aos estudantes.

m) Encaminhamentos para a publicação.

Fonte: elaboração das autoras, 2020. Notícia para crianças, dentro da es-
fera do jornalismo de DC, a ser publicada no maior jornal da cidade e nas redes sociais da feira, bem como divulgadas em exposição na escola e na Imersão Científica e Tecnológica da escola.
Setembro de 2019

Estudos: outubro a dezembro de 2019

Encaminhamentos para a publicação e divulgação: dezembro de 2019 a julho de 2020. 
Como etapa de divulgação do produto final, alguns textos produzidos ultrapassaram os muros da instituição e foram divulgados no maior jornal da cidade. $\mathrm{Da}$ mesma forma, serão divulgados nas redes sociais da feira da escola, ainda no ano de 2020. Assim, o interlocutor do texto não será/está sendo apenas o professor da disciplina de Língua Portuguesa, que propôs o trabalho, mas sim crianças do ensino fundamental da região, que poderão entrar em contato com o conhecimento científico produzido por pequenos cientistas de sua mesma faixa etária e ter ideias para seus trabalhos de pesquisa. Da mesma forma, os próprios autores das pesquisas poderão ver o seu trabalho virar uma notícia produzida por "jornalistas" do ensino médio técnico. Também os professores de ensino fundamental poderão trabalhar com textos autênticos, voltados especialmente para seus alunos. Além disso, toda comunidade poderá ter acesso a esses textos.

\section{Análise dos textos produzidos}

Os estudantes poderiam reunir-se em grupos de sua livre escolha, de, no máximo, quatro componentes. Foram produzidas 27 notícias de divulgação científica midiática, conforme Quadro 2.

Quadro 2 - Os textos produzidos

(continua...)

\begin{tabular}{|l|l|l|l|}
\hline Texto & \multicolumn{1}{|c|}{ Título } & \multicolumn{1}{|c|}{ Subtítulo } & Temática do projeto escolhido \\
\hline 1 & $\begin{array}{l}\text { A doação de órgãos é um } \\
\text { ato de solidariedade }\end{array}$ & $\begin{array}{l}\text { Tem gente há tanto tempo na fila de trans- } \\
\text { plante que o coração não está mais aguen- } \\
\text { tando... }\end{array}$ & Doação de órgãos \\
\hline 2 & Álcool pra criançada? & $\begin{array}{l}\text { Pesquisadoras estudam o consumo de álcool } \\
\text { entre crianças e adolescentes }\end{array}$ & $\begin{array}{l}\text { Uso de álcool entre alunos } \\
\text { da comunidade escolar }\end{array}$ \\
\hline 3 & Alcoolismo entre os jovens & $\begin{array}{l}\text { Estudo feito por adolescentes busca alertar } \\
\text { sobre o uso de bebidas alcoólicas. }\end{array}$ & $\begin{array}{l}\text { Consumo de bebidas alco- } \\
\text { ólicas por jovens entre 14 a } \\
17 \text { anos }\end{array}$ \\
\hline 4 & $\begin{array}{l}\text { Aparelhos eletrônicos, alu- } \\
\text { nos nota zero! }\end{array}$ & $\begin{array}{l}\text { Pesquisadoras do ensino fundamental to- } \\
\text { mam atitude contra o uso excessivo de apa- } \\
\text { relhos eletrônicos }\end{array}$ & $\begin{array}{l}\text { Malefícios do uso excessivo } \\
\text { de aparelhos eletrônicos }\end{array}$ \\
\hline 5 & $\begin{array}{l}\text { Assédio e suas diferentes } \\
\text { formas }\end{array}$ & $\begin{array}{l}\text { Se perguntassem para você hoje "O que é } \\
\text { assédio?", você saberia responder? }\end{array}$ & $\begin{array}{l}\text { Assédio sexual na comuni- } \\
\text { dade do projeto }\end{array}$ \\
\hline 6 & Ausente1 & Ausente & $\begin{array}{l}\text { Inteligência artificial na me- } \\
\text { dicina }\end{array}$ \\
\hline 7 & $\begin{array}{l}\text { Bobinas de Tesla }- \text { ener- } \\
\text { gia elétrica wireless feita } \\
\text { em casa }\end{array}$ & $\begin{array}{l}\text { Ausente } \\
\text { transmissão de energia elé- } \\
\text { trica por meio de campos } \\
\text { eletromagnéticos }\end{array}$ \\
\hline 8 & $\begin{array}{l}\text { Comer ou pintar? Descu- } \\
\text { bra a arte do açaí }\end{array}$ & $\begin{array}{l}\text { Pesquisa de jovens do Pará aponta que é } \\
\text { possível usar o açaí para pintar telas e fazer } \\
\text { as mais variadas tintas, dependendo do in- } \\
\text { grediente que for misturado }\end{array}$ & $\begin{array}{l}\text { Produção de tintas com vá- } \\
\text { rias cores a partir das partes } \\
\text { do açaí }\end{array}$ \\
\hline 9 & $\begin{array}{l}\text { Diversão é pra todo mun- } \\
\text { do! }\end{array}$ & $\begin{array}{l}\text { Ser bom em algum jogo não é só para meni- } \\
\text { nos, é para todos! }\end{array}$ & Esporte e gênero \\
\hline
\end{tabular}


(conclusão)

\begin{tabular}{|c|c|c|c|}
\hline 10 & $\begin{array}{l}\text { Drogas: o que elas cau- } \\
\text { sam? }\end{array}$ & Ausente & $\begin{array}{l}\text { Problemas com o uso de } \\
\text { drogas }\end{array}$ \\
\hline 11 & $\begin{array}{l}\text { Economia circular: uma } \\
\text { nova esperança para o } \\
\text { meio ambiente }\end{array}$ & $\begin{array}{l}\text { Alunos de } 7^{\circ} \text { ano fazem projeto sobre o mé- } \\
\text { todo o método mais eficaz para melhorar o } \\
\text { futuro do meio ambiente. }\end{array}$ & $\begin{array}{l}\text { Método da economia circu- } \\
\text { lar }\end{array}$ \\
\hline 12 & $\begin{array}{l}\text { Estudantes de Venâncio } \\
\text { Aires participam de feira } \\
\text { tecnológica internacional }\end{array}$ & Ausente & Aplicações do gás ozônio \\
\hline 13 & Inteligência artificial & $\begin{array}{l}\text { Como finalistas da (nome da feira, retirado } \\
\text { por questões éticas) conseguiram prever o } \\
\text { preço futuro de uma moeda virtual. }\end{array}$ & $\begin{array}{l}\text { Criação de uma inteligência } \\
\text { artificial para prever o preço } \\
\text { do Bitcoin }\end{array}$ \\
\hline 14 & Lagartixas & Pragas domésticas ou aliadas? & $\begin{array}{l}\text { Função das lagartixas no } \\
\text { meio ambiente }\end{array}$ \\
\hline 15 & $\begin{array}{l}\text { Lixo espacial é um perigo } \\
\text { real? }\end{array}$ & $\begin{array}{l}\text { Alunos do sétimo ano da Escola Municipal } \\
\text { Professor Aderbal Galvão, de Recife, che- } \\
\text { gam à (nome da feira, retirado por questões } \\
\text { éticas) com esse problema }\end{array}$ & Lixo espacial \\
\hline 16 & Lixo, será mesmo? & $\begin{array}{l}\text { Jovens estudam se é possível plantar papel } \\
\text { reciclado através de sementes }\end{array}$ & $\begin{array}{l}\text { Papel reciclado e plantação } \\
\text { de árvores }\end{array}$ \\
\hline 17 & $\begin{array}{l}\text { O caminho da cenoura até } \\
\text { o Pernalonga }\end{array}$ & $\begin{array}{l}\text { Alunos recuperam horta de escola, e a curio- } \\
\text { sidade pela cenoura traz grandes descobertas }\end{array}$ & De onde vêm as cenouras \\
\hline 18 & O que é o antúrio? & $\begin{array}{l}\text { Alunas do ensino fundamental de Montene- } \\
\text { gro fazem projeto desvendando os mistérios } \\
\text { da planta antúrio }\end{array}$ & As partes do antúrio \\
\hline 19 & $\begin{array}{l}\text { P.A.R.: um projeto econô- } \\
\text { mico e sustentável }\end{array}$ & $\begin{array}{l}\text { O Projeto Água Reutilizável tem como objeti- } \\
\text { vo a economia de água e, consequentemen- } \\
\text { te, a diminuição da conta no fim do mês }\end{array}$ & $\begin{array}{l}\text { Produção de um reservatório } \\
\text { móvel para captar a água } \\
\text { descartada pela máquina de } \\
\text { lavar roupa e sua reutilização }\end{array}$ \\
\hline 20 & $\begin{array}{l}\text { Perigosos canudos plás- } \\
\text { ticos }\end{array}$ & $\begin{array}{l}\text { Conheça o trabalho "Descanude-se", partici- } \\
\text { pante da (nome da feira, retirado por ques- } \\
\text { tões éticas). Entenda sobre os danos cau- } \\
\text { sados pelos canudinhos no mundo em que } \\
\text { você vive }\end{array}$ & $\begin{array}{l}\text { Tipos de canudos que são } \\
\text { melhores para o meio am- } \\
\text { biente }\end{array}$ \\
\hline 21 & $\begin{array}{l}\text { Quais os perigos dos bichi- } \\
\text { nhos de jardim? }\end{array}$ & $\begin{array}{l}\text { Sendo vilões ou heróis, todos têm sua função } \\
\text { e são importantes para o ambiente }\end{array}$ & $\begin{array}{l}\text { A função dos insetos do jar- } \\
\text { dim }\end{array}$ \\
\hline 22 & $\begin{array}{l}\text { Robôs médicos, já pensou } \\
\text { nisso? }\end{array}$ & Inteligência artificial na medicina & $\begin{array}{l}\text { Inteligência artificial na me- } \\
\text { dicina }\end{array}$ \\
\hline 23 & $\begin{array}{l}\text { Será que as aranhas po- } \\
\text { dem ser super-heroínas? }\end{array}$ & $\begin{array}{l}\text { Uma turma do } 4^{\circ} \text { e do } 5^{\circ} \text { ano de Dois Irmãos } \\
\text { queria saber mais sobre as teias e acabou } \\
\text { descobrindo que as aranhas podem ser nos- } \\
\text { sas aliadas contra inimigos mais perigosos } \\
\text { que o Duende Verde }\end{array}$ & $\begin{array}{l}\text { A produção das teias de ara- } \\
\text { nhas }\end{array}$ \\
\hline 24 & $\begin{array}{l}\text { Transformes poderão subs- } \\
\text { tituir médicos no futuro? }\end{array}$ & $\begin{array}{l}\text { Pesquisa mostra como a inteligência artificial } \\
\text { mudará a medicina no futuro }\end{array}$ & $\begin{array}{l}\text { Inteligência artificial na me- } \\
\text { dicina }\end{array}$ \\
\hline 25 & $\begin{array}{l}\text { Uma cor define nosso gê- } \\
\text { nero? }\end{array}$ & $\begin{array}{l}\text { Pesquisa em escola de São Leopoldo } \\
\text { mostra resultados impressionantes sobre o } \\
\text { sobre o assunto. }\end{array}$ & $\begin{array}{l}\text { Gênero, infância e preferên- } \\
\text { cia por cor }\end{array}$ \\
\hline 26 & $\begin{array}{l}\text { Você sabia que os animais } \\
\text { marinhos estão morrendo? }\end{array}$ & Ausente & $\begin{array}{l}\text { Criação de canudos reciclá- } \\
\text { veis com a cana de açúcar }\end{array}$ \\
\hline 27 & $\begin{array}{l}\text { Você sabia que vários ani- } \\
\text { mais são mortos todos os } \\
\text { dias na BR-116? }\end{array}$ & $\begin{array}{l}\text { Ideia genial de jovens estudantes pode sal- } \\
\text { var a vida de vários animaizinhos!!!!!!!! }\end{array}$ & $\begin{array}{l}\text { Alta mortalidade de animais } \\
\text { na BR-116 }\end{array}$ \\
\hline
\end{tabular}

Fonte: elaboração das autoras, 2020. 
Para Bakhtin, são três os elementos constitutivos dos gêneros discursivos: conteúdo temático, construção composicional e estilo. Nesta análise, a ênfase será dada ao estilo e, dentro desse aspecto, às estratégias patêmicas estudadas a partir de Nunes (2019). Como o interlocutor principal dos textos são/serão jovens leitores, que talvez não dominem os conceitos científicos abordados, é necessário que a linguagem seja leve e clara. Não cabem jargões científicos; as expressões típicas da ciência precisam ser explicadas, por meio de definições, exemplos, comparações ou analogias. A seguir, citam-se três fragmentos produzidos pelos estudantes que ilustram momentos em que isso ocorre:

Pensando nisso, nossos super-heróis mirins se puseram a construir Bobinas de Tesla, invenções_capazes de transmitir energia elétrica pelo ar. Dessa maneira, não existiriam cabos ou fios atrapalhando. [...]. As Bobinas de Tesla foram criadas em 1891 por Nikola Tesla como um método de transmitir energia elétrica por meio de campos eletromagnéticos, ou seja, sem cabos. São cilindros revestidos de fios, geralmente de cobre, que recebem energia e a transmitem pelo ar até atingir outra bobina (Texto 7) (Grifo nosso).

Antes da pesquisa começar, pensavam que a flor do antúrio era sua bráctea, que é a parte colorida e que tem o formato parecido com o das folhas. Ao pesquisarem descobriram que a verdadeira flor do antúrio é minúscula, tendo o tamanho da cabeça de um alfinete, e fica em torno da espiga (Texto 18) (Grifo nosso).
É melhor estar bem informado mesmo sobre os aracnídeos, aqueles seres invertebrados que possuem 8 patas, como, por exemplo, as aranhas, e sobre os insetos, invertebrados de 6 patas [...] (Texto 21) (Grifo nosso).

No primeiro exemplo, diante de um conceito provavelmente novo para o leitor, as bobinas de Tesla, os autores explicam o que é a invenção por meio de um aposto, na primeira frase. Nas frases seguintes, fazem uma descrição do objeto e ainda explicam o que é transmissão de energia por meio de campo magnético. No segundo exemplo, os autores explicam a definição de bráctea, por meio de duas orações subordinadas adjetivas. Da mesma forma, comparam o tamanho da flor com algo, provavelmente, bastante conhecido do leitor: a cabeça de um alfinete. Por fim, o terceiro exemplo explica, por meio de apostos, o significado dos termos aracnídeos e insetos.

O próximo elemento de análise, ainda dentro do estilo, são as estratégias patêmicas estudadas para atingir o duplo objetivo já mencionado: informar e captar a atenção. Para isso, elaborou-se um quadro-resumo com as estratégias linguístico-discursivas citadas por Nunes (2019) e com exemplos de cada uma delas retirados dos textos dos estudantes. Evidentemente, não estão mencionadas todas as ocorrências utilizadas pelos estudantes, o que ultrapassaria os limites deste artigo, porém selecionou-se, no mínimo, um exemplo de cada estratégia, pois todas foram utilizadas por eles² (Quadro 3). 
a) Abertura explosiva (início do texto em forma de pergunta)

b) Uso de interjeições

c) Expressões avaliativas e qualificadoras (Ex.: extremamente importante, ambiente incrível...)

d) Palavras e expressões encontradas em histórias infantis

e) Situações que suscitam o nojo ou embaraço/desastres

f) Humor

g) Fantasias/personagens com que se identificam

h) Vitórias na adversidade/bem vence o mal

"Já é legal juntarmos a arte e a ciência, não? Mas você já pensou em aglomerar comida e ciência? Ou melhor, comida, arte e ciência?" (Texto 8).

"Você conhece o antúrio? Sabe dizer onde fica a flor da planta? Se as respostas foram negativas, aposto que você adoraria descobrir" (Texto 18)

"Seria como ser atingido por um raio. Ai!" (Texto 7).

"Imagina encostar em um bichinho que faz mal para nós, ui, ninguém merece" (Texto 21).

"Eles plantaram deliciosas cenouras na horta e, depois de elas crescerem, viram que, dessas plantinhas, saíam flores que depois viravam sementes! E também, depois de mais algum tempo, essas sementes viravam novas cenouras!" (Texto 17).

"Pesquisa em escola de São Leopoldo mostra resultados impressionantes sobre o assunto" (Texto 25).

"A doação de órgãos pode ser muito bem explicada através da história da tartaruga sem casco" (Texto 1).

"Descobriram também que, como qualquer invenção maluca vista nos quadrinhos ou desenhos, a invenção deles não era sem seus riscos" (Texto 7).

"Quase todo mundo tem medo nojo de lagartixas, não é mesmo? As pessoas podem achá-las feias ou até capazes de transmitir alguma doença" (Texto 14).

"Um robô que auxilia o médico em trabalhos como pegar uma tesoura ou uma agulha, até podendo estar encarregado de fazer trabalhos que o médico faria, como coletar uma amostra de sangue ou até fazer exame de fezes, aqueles exames que tem um pote com cocô, eca que nojo!" (Texto 22).

"Você já tentou assustar uma lagartixa para que ela perca sua cauda?" (Texto 14).

"Diretamente do universo da DC Comics, o herói Super-Choque, extremamente popular no Brasil por conta de seu desenho animado, tem a capacidade de gerar descargas elétricas. Além disso, ele consegue criar campos eletromagnéticos que o permitem levitar, atirar bolas de energia e rajadas de eletricidade em seus inimigos" (Texto 7).

"Você já pensou de onde vêm as cenouras de que o nosso amigo Pernalonga tanto gosta?" (Texto 17).

"[...] existiam aqueles insetos que eram realmente bons, os heróis; aqueles que, mesmo fazendo o bem nos afetam, os anti-heróis; e aqueles que realmente são perigosos e que têm um benefício mínimo, os vilões, malvados como o Thanos e brabos como o Magneto, mas bem menores" (Texto 21).

"Uma turma do $4^{\circ}$ e do $5^{\circ}$ ano de Dois Irmãos queria saber mais sobre as teias e acabou descobrindo que as aranhas podem ser nossas aliadas contra inimigos mais perigosos que o Duende Verde" (Texto 23).

"Sim, muitos bichinhos, como o Scooby Doo, morrem todos os anos na rodovia e até agora ninguém fez algo para diminuir esse número" (Texto 27).

"Assim como o Super-Choque, herói das ruas, fazia uso de campos eletromagnéticos na sua luta contra o crime, os meninos de Lajeado foram verdadeiros super-heróis ao tentarem resolver problemas reais" (Texto 7).

"Os alunos do 5 ano da escola Pequeno Príncipe, do município de São Leopoldo, queriam lutar contra esse vilão, o desperdício de papel e o problemão que causava ao meio ambiente [...] Ao final o objetivo foi concluído [...] e a poluição ao meio ambiente foi derrotada" (Texto 16).

"Uma turma do $4^{\circ}$ e do $5^{\circ}$ ano de Dois Irmãos queria saber mais sobre as teias e acabou descobrindo que as aranhas podem ser nossas aliadas contra inimigos mais perigosos que o Duende Verde" (Texto 23).

Revista do Programa de Pós-Graduação em Letras da Universidade de Passo Fundo, v. 16, n. 3, p. 473-490, set./dez. 2020 
i) Fatos inusitados/descobertas fascinantes/surpresas

j) Ludicidade (brincar com palavras expressões, imagens)

k) Aspectos vividos pela criança/ acontecimentos próprios do universo infantil

1) Referências ao interlocutor (uso do pronome "você", verbos no imperativo)

m) Emprego de frases interrogativas ou frases exclamativas tionamentos ou avaliações do leitor mirim

o) Chamada de atenção para o fato de que o leitor mirim aprendeu algo novo (Valorização do conhecimento científico)

p) Antropomorfização de elementos

q) Uso da linguagem próxima do cotidiano/léxico da criança n) Antecipações de possíveis ques da natureza

"Antes da pesquisa começar, pensavam que a flor do antúrio era sua bráctea, que é a parte colorida e que tem o formato parecido com o das folhas. Ao pesquisarem descobriram que a verdadeira flor do antúrio é minúscula, tendo o tamanho da cabeça de um alfinete e fica em torno da espiga" (Texto 18).

"Pode parecer pouco, mas você se surpreenderia com o tanto que isso polui o planeta. Ele não é biodegradável, o que significa que ele pode levar até mil anos para se decompor. Isso mesmo, MIL ANOS!!" (Texto 20).

"Após a situação frustrante, elas decidiram que já era hora de botar a mão na massa [...]" (Texto 9)

"Álcool pra criançada?" (Texto 2).

"Imagine quantas vezes você deixou de dormir 10 ou 30 minutos porque ficou assistindo Netflix, jogando jogos ou respondendo aos amigos no WhatsApp. Os números são grandes quando somados vários dias. Para aguentar aquele professor que você detesta no outro dia, é necessário dormir bastante! Claro, sem exagerar" (Texto 4).

"[...] e ainda sem o seu Playstation" (Texto 10)

"E você, reutiliza o lixo produzido na sua casa?" (Texto 11).

"Conheça o trabalho 'Descanude-se', participante da (nome da feira, retirado por questões éticas). Entenda sobre os danos causados pelos canudinhos no mundo em que você vive" (Texto 20).

"Você sabe o que é inteligência artificial?! As alunas Ana Clara Michelon Gomes, Larissa Pioner Canali e Valesca Zanfonatto Cecatto, do $9^{\circ}$ ano do Colégio La Salle Carmo, de Caxias do Sul, sabem, e sabem muito!" (Texto 6 ).

"Você já se perguntou quanta água é gasta todos os dias em sua casa? Ou melhor, o quanto dessa água é desperdiçada?" (Texto 19).

"A maioria das pessoas diria que assédio é quando um homem faz algo que não deveria com uma mulher, mas o assédio pode também ser cometido por uma mulher!!” (Texto 5).

"Como assim usar o celular pode atrapalhar o aprendizado? Ou assistir TV? Ou jogar videogame?" (Texto 4).

"Mas você deve estar se perguntando: o que é inteligência artificial?" (Texto 24).

"Agora que você já sabe que tantos satélites podem ser prejudiciais para a humanidade, aposto que nunca mais verá seu $3 G$ da mesma maneira, certo?" (Texto 15).

"Então, para evitar a morte dos bichinhos, o grupo criou canudinhos recicláveis com cana-de-açúcar. Você já tinha pensado que aquele docinho tão bom poderia ajudar a evitar a morte das tartaruguinhas marinhas e dos peixinhos?" (Texto 26)

"Então, convencidos de que as aranhas podem dar uma de Homem-Aranha?" (Texto 23).

"Você já se perguntou se os bichinhos que encontramos nosso jardim ou quintal são do bem ou do mal? [...] A turma, através de muita pesquisa descobriu que as abelhas, lagartixas, borboletas, minhocas e joaninhas são nossos Homem-Aranha da vez, os heróis. Os anti-heróis são, por exemplo, moscas, escorpiões, mosquitos, lagartas e taturanas como o Venom, que faz as coisas para ajudar, mas são perigosos igual, e os vilões são bichos como as aranhas, baratas, formigas e os famosos fede-fedes, ai, que têm um cheiro horrível" (Texto 21).

Fonte: elaboração das autoras com base em Nunes (2019) 
Ao realizar uma análise desse quadro e dos textos produzidos, foi possível perceber que apenas dois textos, os de número 3 e 12, não utilizaram estratégias patêmicas mesmo com sugestões feitas na versão inicial do texto, seja pela professora, seja pelos colegas avaliadores. Limitaram-se a contar sobre o projeto, sem preocupação com as estratégias estudadas. Os autores do texto 12 , inclusive, entregaram sua versão final exatamente igual à inicial. Entretanto, essa mesma análise também mostra que os autores de 25 textos, ou seja, cerca de 92\%, souberam apropriar-se das estraté- gias estudadas. Entre as estratégias que mais se destacaram, em uma avaliação quantitativa, foram aberturas explosivas, interações com o leitor e uso de exclamações ou interrogações.

\section{A interação com os colegas avaliadores}

Uma das últimas etapas da proposta foi a revisão dos textos. Nesse momento, cada grupo deveria ler o texto dos colegas e apontar, se fosse o caso, sugestões para aprimorar as notícias, a partir de uma ficha de avaliação, reproduzida no Quadro 4.

Quadro 4 - Ficha de avaliação

(continua...)

\begin{tabular}{|c|c|}
\hline \multirow{2}{*}{ 1. Capa } & CONTRIBUIÇÕES \\
\hline & \\
\hline \multicolumn{2}{|l|}{ 2. Título e subtítulo } \\
\hline \multicolumn{2}{|l|}{ 3. Lide e corpo da notícia } \\
\hline \multicolumn{2}{|l|}{ a) $3 \mathrm{Q}+\mathrm{COP}^{3}$} \\
\hline \multicolumn{2}{|l|}{$\begin{array}{l}\text { b) Uso de vocabulário próprio da ciência com explicações desses termos } \\
\text { para um público não especialista }\end{array}$} \\
\hline \multicolumn{2}{|l|}{ 4. Estratégias de atração do interesse da criança } \\
\hline a) Abertura explosiva & \\
\hline b) Uso de interjeições & \\
\hline $\begin{array}{l}\text { c) Expressões avaliativas e qualificadoras (Ex.: extremamente importante, } \\
\text { ambiente incrível...) }\end{array}$ & \\
\hline d) Palavras e expressões encontradas em histórias infantis & \\
\hline e) Situações que suscitam o nojo ou embaraço/desastres & \\
\hline f) Humor & \\
\hline g) Fantasias/personagens com que se identificam & \\
\hline h) Vitórias na adversidade/bem vence o mal & \\
\hline i) Fatos inusitados/descobertas fascinantes/surpresas & \\
\hline j) Ludicidade (brincar com palavras, expressões, imagens) & \\
\hline k) Aspectos vividos pela criança/acontecimentos próprios do universo infantil & \\
\hline 1) Referências ao interlocutor (uso do pronome "você", verbos no imperativo) & \\
\hline m) Emprego de frases interrogativas ou frases exclamativas & \\
\hline n) Antecipações de possíveis questionamentos ou avaliações do leitor mirim & \\
\hline
\end{tabular}


(conclusão)

\begin{tabular}{|l|l|}
\hline $\begin{array}{l}\text { o) Chamada de atenção para o fato de que o leitor mirim aprendeu algo } \\
\text { novo (Valorização do conhecimento científico) }\end{array}$ & \\
\hline p) Antropomorfização de elementos da natureza & \\
\hline q) Uso da linguagem próxima do cotidiano/léxico da criança & \\
\hline 5. Foto (com a presença de todos os componentes do grupo) e legenda & \\
\hline 6. Apresentação/Formatação & \\
\hline 7. Revisão gramatical & \\
\hline
\end{tabular}

Fonte: elaboração das autoras com base em Nunes (2019).

O Quadro 5 exemplifica algumas das sugestões dos estudantes feitas nessa ficha, acompanhadas de fragmentos das versões inicial e final dos textos em que as sugestões se inserem.

Quadro 5 - Comparações entre textos iniciais e finais

(continua...)

\begin{tabular}{|c|c|c|c|}
\hline Texto & Versão inicial & $\begin{array}{l}\text { Sugestão dada pelos } \\
\text { colegas }\end{array}$ & Versão final \\
\hline 20 & $\begin{array}{l}\text { "Os canudos são utilizados des- } \\
\text { de muito tempo antes de você } \\
\text { existir, mas a mudança para os } \\
\text { modelos de plástico foi uma pés- } \\
\text { sima escolha, já que trouxe junto } \\
\text { um grande problema no ambien- } \\
\text { te em que vivemos: a poluição." }\end{array}$ & $\begin{array}{l}\text { Abertura explosiva: "Não } \\
\text { usaram. Sugestão: Você } \\
\text { sabia que as lindas tar- } \\
\text { taruguinhas do mar não } \\
\text { ficam felizes com canu- } \\
\text { dos plásticos?" }\end{array}$ & $\begin{array}{l}\text { "Você sabia que as tartaruguinhas que ve- } \\
\text { mos em Procurando Nemo não ficam nada } \\
\text { felizes com os canudos plásticos? Os canu- } \\
\text { dinhos são utilizados desde muito tempo an- } \\
\text { tes de você existir, mas a mudança para os } \\
\text { modelos de plástico foi uma péssima esco- } \\
\text { lha, já que trouxe junto um grande problema } \\
\text { no ambiente em que vivemos: a poluição." }\end{array}$ \\
\hline 13 & $\begin{array}{l}\text { "Já imaginou se pudesse pre- } \\
\text { ver o futuro de algo? Seria bem } \\
\text { bacana não? Pois foi o que } \\
\text { três alunos finalistas da (nome } \\
\text { da feira, retirado por questões } \\
\text { éticas) da Escola Internacional } \\
\text { UniSociesc, da Cidade de Flo- } \\
\text { rianópolis, fizeram." } \\
\text { Ausente }\end{array}$ & $\begin{array}{l}\text { 3Q+COP: Faltou dizer } \\
\text { quem (ficou vago). }\end{array}$ & $\begin{array}{l}\text { "Já imaginou se pudesse prever o futuro } \\
\text { de algo? Seria bem bacana não? Pois foi } \\
\text { o que esses três alunos finalistas (Sofia } \\
\text { Veiga, Gabriel Lindner e Caio Petrocini) da } \\
\text { (nome da feira, retirado por questões éti- } \\
\text { cas) da Escola Internacional UniSocies, } \\
\text { da Cidade de Florianópolis, fizeram." } \\
\text { "Agora que você sabe como ele funciona, } \\
\text { falta explicar como eles usaram esse co- } \\
\text { nhecimento para prever o preço, pois bem, } \\
\text { usando o Twitter, um site onde você pode } \\
\text { se expressar através de poucas palavras, } \\
\text { pegaram vários tweets, como são chama- } \\
\text { dos, relacionados ao assunto da questão } \\
\text { do seu preço, tirando assim uma média de } \\
\text { cada mês respectivamente." }\end{array}$ \\
\hline 15 & $\begin{array}{l}\text { "Todos os dias ouvimos como } \\
\text { a sustentabilidade é importan- } \\
\text { te para o nosso futuro e para a } \\
\text { sobrevivência da raça humana, } \\
\text { porém é muito difícil que você já } \\
\text { tenha ouvido falar sobre o lixo } \\
\text { espacial." }\end{array}$ & $\begin{array}{l}\text { Emprego de frases in- } \\
\text { terrogativas ou excla- } \\
\text { mativas: "Pode incluir } \\
\text { uma frase como "Você } \\
\text { já se imaginou vivendo } \\
\text { no espaço?" }\end{array}$ & $\begin{array}{l}\text { "Você já se imaginou vivendo no espaço? } \\
\text { Sabia que, para uma futura sobrevivência } \\
\text { da humanidade em outros planetas, a sus- } \\
\text { tentabilidade também é importante? Bom, } \\
\text { todos nós estamos já cansados de ouvir } \\
\text { todos os dias sobre como a sustentabilida- } \\
\text { de é importante para o nosso futuro e para } \\
\text { a sobrevivência da raça humana, porém é } \\
\text { muito difícil que você já tenha ouvido falar } \\
\text { sobre lixo espacial." }\end{array}$ \\
\hline
\end{tabular}




\begin{tabular}{|c|c|c|c|}
\hline 21 & $\begin{array}{l}\text { "A turma B, faixa etária de } 5 \\
\text { anos da E.M.E.F. Irmão Nilo, } \\
\text { Novo Hamburgo, turno da tarde, } \\
\text { alunos da professora Cátia de } \\
\text { Oliveira, ao verem uma taturana } \\
\text { [...]" } \\
\text { Ausente }\end{array}$ & $\begin{array}{l}\text { Uso de interjeições: } \\
\text { "Seria bem legal de } \\
\text { usar, pois fala sobre } \\
\text { insetos. 'Ui, imagina se } \\
\text { você encontrasse um } \\
\text { desses?"” } \\
\text { Situações que suscitam } \\
\text { o nojo ou embaraço/de- } \\
\text { sastres: Teve um pouco } \\
\text { disso, mas poderia ser } \\
\text { mais abordado para os } \\
\text { insetos que eles não po- } \\
\text { dem tocar. } \\
\text { Antecipações de possí- } \\
\text { veis questionamentos } \\
\text { ou avaliações do leitor } \\
\text { mirim: "Agora você deve } \\
\text { estar se perguntando: } \\
\text { como os pesquisadores } \\
\text { conseguiram descobrir } \\
\text { quais insetos faziam } \\
\text { bem ou mal?" }\end{array}$ & $\begin{array}{l}\text { "Imagina encostar em um bichinho que faz } \\
\text { mal para nós, ui, ninguém merece." } \\
\\
\text { "Agora que já sabe tanto sobre os tipos } \\
\text { de insetos e aracnídeos que temos, você } \\
\text { deve estar se perguntando quem são es- } \\
\text { ses tais de vilões e heróis!" }\end{array}$ \\
\hline
\end{tabular}

Fonte: elaboração das autoras, 2020.

Esses são apenas alguns dos exemplos que ilustram as trocas entre os grupos. Entretanto, já demonstram que o olhar do outro pode contribuir para $o$ crescimento desse texto. Porém, nem todas as sugestões foram acatadas por todos.

\section{Pontos a serem repensados}

Parte-se da concepção de que é necessário sempre avaliar o processo de ensino para rever alguns pontos para as próximas oportunidades. A proposta pedagógica foi bastante profícua, pois, além de discutir ciência e divulgação da ciência, ainda possibilitou aprofundar o conhecimento que esses estudantes têm sobre língua oral e escrita - principalmente na adequação de seu discurso ao interlocutor - em uma proposta articulada às suas práticas sociais. Entretanto, alguns pontos podem ser repensados.

$\mathrm{O}$ primeiro deles diz respeito às sugestões feitas pelos grupos ao texto dos colegas. Por vezes, houve correções de supostos "erros" que não existiam. O papel da professora foi assinalar que o grupo ignorasse aquela sugestão. Outro ponto 
poderia ser a inserção de mais momentos de discussão dos textos produzidos, com seções coletivas de reescritas de fragmentos ou até a inclusão de momentos em sala de aula para a produção desses textos. Da mesma forma, a abordagem de elementos para uma reflexão linguística também poderia ter sido explorada a partir dos textos.

Outra questão é o fato de que alguns textos demonstraram, mesmo na versão final, uma mistura da linguagem da DCM com a linguagem científica. Veja-se o exemplo a seguir:

Sobre os estudos feitos em aula Thaiz (2019) diz que "As produções das pinturas aconteceram em torno dos estudos de temas da história da arte como: movimentos da vanguarda europeia, barroco, pinturas Adinkras e memória coletiva, mantendo a relação da arte com a cultura amazônica. [...]. Os alunos pintaram suas ideias nas telas, tomando como elemento principal o açaí. Ora misturando-o com cola branca ora com outros pigmentos e materiais naturais como o limão. O objetivo era trazer o açaí para dentro da arte, fazer as pessoas verem que ele não tem apenas a função alimentícia" (Texto 8).

É possível perceber uma preocupação com as normas de citação, com o ano colocado entre parênteses, mesmo na versão final. Na versão inicial, o grupo chegou a recuar a fala da pesquisadora a quatro centímetros da margem, como impõe o texto acadêmico para citações longas. Na versão final, apenas tiraram a formatação recuada e assim deixaram a fala com o ano. Da mesma forma, depois das fotos, a "legenda" era "Fonte: o autor (2019)", marcas típicas do discurso acadêmico, com que eles haviam trabalhado meses antes para a produção de um texto pertencente a outro gênero.

Por fim, é importante ressaltar uma preocupação - e que precisa cada vez mais ser discutida na elaboração de propostas pedagógicas: aquilo que Barbosa e Rovai (2012, p. 19) chamam de "abandono de trabalho com textos em função de um trabalho com as propriedades dos gêneros", em uma tendência de, por exemplo, estruturalizar o gênero e considerar somente seus aspectos formais, a "cristalizar" excessivamente o gênero ou tomá-lo em uma perspectiva normativa. Nesse caso, trabalhou-se com as propriedades formais da notícia de DCM, mas não para formar aquilo que as autoras chamam de "especialistas em gêneros (ou repetidores de suas características)" (BARBOSA; ROVAI, 2012, p. 19). O objetivo foi discutir o papel da ciência e da DCM em uma sociedade democrática e o fato de que eles, como futuros cientistas (para se formarem na escola, precisarão desenvolver, no mínimo, um projeto científico e divulgá-lo), precisarão se preocupar com a linguagem utilizada para interagir com o outro cientista, mas com o não especialista. Procurou-se enfatizar a importância da prática social em que eles estavam inseridos para a produção do texto que foi o produto final. Essa foi uma oportunidade de iniciar essa discus- 
são com esses estudantes, debate esse que precisa ser continuamente ampliado em futuras propostas.

\section{Science popularization and} Portuguese language education: reflections on teaching and learning writing in high school

\section{Abstract}

Many Brazilian schools have already adopted a teaching methodology through research, contributing thus to the scientific literacy of the students. In this context, it is the role of the elementary school to provide opportunities for researcher-students to, besides popularizing their research to their peers, also popularize it to a non-specialist audience. This paper discusses the results of a pedagogical proposal that sought to bring science popularization to the classroom in a mother tongue class. The proposal, applied in a public technical high school, culminated in the production of written news as a discourse genre in the sphere of science popularization journalism. The results showed the importance of working with science popularization and reaffirmed the necessity for language education curriculum design to be linked to social practices. Besides, the experience reinforced the importance of interaction between teacher and students and, also, between the students themselves.

Keywords: Portuguese language teaching. Discoursive genres. Science popularization.

\section{Notas}

1 Optou-se por utilizar a nomenclatura "Ausente", em todos os quadros apresentados, quando o grupo não redigiu um dos elementos da estrutura da notícia.

2 Em outro artigo, Campani e Nunes (no prelo), após analisarem todos os textos produzidos pelos estudantes em relação a estratégias patêmicas com elementos quantitativos, chegam à conclusão de que o que mais se destacou foram as ocorrências relacionadas à interação com o leitor (Ato Alocutivo, dentro da teoria Semiolinguística). O propósito de tal artigo, portanto, difere-se do deste texto.

3 Quem? Fez o quê? Quando? Como? Onde? Por quê?

\section{Referências}

BAKHTIN, M. Estética da criação verbal. 4. ed. São Paulo: Martins Fontes, 2003.

BARBOSA, J. P.; ROVAI, C. F. Gêneros do discurso na escola: rediscutindo princípios e práticas. São Paulo: FTD, 2012.

BRASIL. Ministério da Educação. Base Nacional Comum Curricular. Brasília, DF: MEC, 2017.

CAMPANI, D.; NUNES, D. O Ato Alocutivo em notícias de divulgação da ciência produzidas por alunos de ensino médio: entre o informar e o captar. No prelo.

CHAGAS, C. Lagarto esquentadinho. Ciência Hoje das Crianças. 4 fev. 2016. Disponível em: http://chc.org.br/lagarto-esquentadinho/. Acesso em: 20 out. 2019.

FARACO, C. A. Linguagem \& diálogo: as ideias linguísticas do círculo de Bakhtin. São Paulo: Parábola Editorial, 2009.

ESTUDO explica por que cachorros são sensíveis e sociáveis. Revista Galileu. 21 set. 2017. Disponível em: https://revistagalileu.globo. com/Ciencia/noticia/2017/09/estudo-explica-por-que-cachorros-sao-sensiveis-e-sociaveis. html. Acesso em: 2 out. 2019. 
GIERING, M. E.; SOUZA, J. A. S. Informar e captar: objetos de discurso em artigos de divulgação científica para crianças. In: CAVALCANTE, M. M.; LIMA, C. M. C.;

MARQUESI, S. C. Referenciação: teoria e prática. São Paulo: Cortez, 2013. p. 205-232.

LORETTO, D. Ai, que fedor!. Ciência Hoje das Crianças. 13 jan. 2016. Disponível em: http://chc.org.br/ai-que-fedor/. Acesso em: 20 out. 2019.

NUNES, D. S. Estratégias patêmicas em artigos de popularização da ciência para crianças no domínio midiático digital. 2019. 209 f. Dissertação (Mestrado em Linguística Aplicada) - Programa de Pós-Graduação em Linguística Aplicada, Unisinos, São Leopoldo, 2019.

VOGT, C. A espiral da cultura científica. Comciência. 2003. Disponível em: http:// www.comciencia.br/dossies-1-72/reportagens/cultura/cultura01.shtml. Acesso em: 11 dez. 2019.

SCLIAR, M. Imaginário cotidiano. São Paulo: Global Editora, 2001.

SILVA, J. Z. Contribuições dos estudos de letramento científico para as práticas de pesquisa na educação básica. Dissertação (Mestrado em Letras) - Programa de Pós-Graduação em Letras, UFRGS, Porto Alegre, 2020.

SIMÕES, L. J. et al. Leitura e autoria: planejamento em Língua Portuguesa e Literatura. Erechim: Edelbra, 2012.

TARCIA, L. A difícil relação entre sono do adolescente, humor e horário escolar. Minas Faz Ciência Infantil. 19 abr. 2018. Disponível em: https://minasfazciencia.com.br/infantil/2019/09/10/fungos-para-a-saude-bucal/. Acesso em: 20 out. 2019.

SOARES, V. De onde vem a sensação boa de quando matamos a sede? Minas Faz Ciência Infantil. 22 jul. 2019a. Disponível em: http://minasfazciencia.com.br/infan- til/2019/07/22/matar-a-sede/. Acesso em: 20 out. 2019.

SOARES, V. Fungos para a saúde bucal?! Minas Faz Ciência Infantil. 10 set. 2019b. Disponível em: https://minasfazciencia.com. br/infantil/2019/09/10/fungos-para-a-saude-bucal/. Acesso em: 20 out. 2019.

ZAMBONI, L. M. S. Cientistas, jornalistas e a divulgação científica: subjetividade e heterogeneidade no discurso de divulgação científica. Campinas: Autores Associados, 2001. 